\title{
The interaction of word complexity and word duration in an agglutinative language
}

\author{
Mária Gósy ${ }^{1}$, Kálmán Abari ${ }^{2}$ \\ ${ }^{1}$ Linguistics Institute, Eötvös Loránd Research Centre, Budapest, Hungary \\ ${ }^{2}$ Institute of Psychology, University of Debrecen, Debrecen, Hungary \\ gosy.maria@nytud.hu, abari.kalman@arts.unideb.hu
}

\begin{abstract}
The mental lexicon comprises the representations of various words either in a morphologically decomposed form, or in a conceptually non-decomposed form. The durations of monomorphemic and multimorphemic words are assumed to contain information on the routes of their lexical access.

The durations of Hungarian nouns with various lengths produced spontaneously by 10 young and 10 elderly speakers (with 55 years of difference between them) were measured. Findings showed significant differences depending on the words' complexity and on age. The nouns both with and without suffixes were significantly longer in old than in young speakers. The durational differences depending on age were more pronounced in monomorphemic nouns as opposed to multimorphemic nouns. Along with the increasing number of syllables of the nouns, old speakers produced increasingly longer simple nouns (stems) than young ones did.

We suggest that multimorphemic nouns are accessed decompositionally in spontaneous utterances when the stem activation is followed by the activation of the suffixes. The specific storage and the corresponding lexical access of the morphemes explain the longer durations of the inflected nouns.

Index Terms: noun durations, monomorphemic, multimorphemic nouns, young and old speakers, spontaneous speech
\end{abstract}

\section{Introduction}

The words of an agglutinative language may contain several different morphemes (stems and various suffixes) that result in a number of syllables in a word form. Due to the very complex morphology these words are relatively long and may easily contain more than 6 syllables. Although the language-specific rules of word structure are defined (e.g., the order of suffixes following the stem), the lexical representations of the suffixed words raise various questions concerning both storage and activation.

Lexical representations of the word forms are assumed to be stored either in a morphologically decomposed form, or in a conceptually non-decomposed form [1], [2], [3], [4]. The theory of decomposed storage assumes that morphemes are stored separately in the mental lexicon. This claim was reported based on experimental evidence in the literature [5], [6]. The idea of non-decomposed storage assumes that the words are redundantly stored in their fully inflected forms [7], [8].

Lexical activation of words in spontaneous utterances may be different depending on their morphological complexity. The decompositional route of lexical access means that monomorphemic words (containing only a stem) are activated according to their representations while multimorphemic words (suffixed stems) are accessed according to their morpheme representations. During the early phases in language acquisition children use and access both regular and irregular word forms the same way since their mental lexicon contains both forms [9], [10]. Findings with morphologically non-decomposable nonwords supported that they were more easily processed than nonwords with partial morphological structure based on reaction time and error performance analyses [1].

During the past decades, theoretical models, computer simulations, and empirical research have provided a large body of findings to confirm either the decomposed or the nondecomposed routes for activation of the mental lexicon without any consensus so far. Both routes of lexical access have been reported to exist in speech production of various languages like English, Russian, German, Chinese, and French [5], [6], [11], [12], [13], [14]. There is a currently emerging assumption on word processing that tries to interpret lexical access as the result of simultaneously activating patterns [12]. Findings confirmed the decomposed route for semantically transparent English words while the conceptually non-decomposed route for semantically opaque word forms (these latter ones behaved as monomorphemic words) [15]. The highly inflected Russian language characteristically uses a decomposition route during the first stage of word identification [6]. According to Saxton [16] regular past tense forms of English verbs are generated by a rule while irregular verbs are stored as a unit. English verbs of regular and irregular past-tense forms were examined using ERP [17]. The observed ERP responses suggested that some combinatorial processing was characteristic of regular but not of irregular past-tense formation. The latter forms are assumed to be represented as a list of exceptions [18]. The routes of possibly different activation of words with simple and complex morphological constructions, however, are a matter of debate.

There is only a small branch of research that focuses on the word durations as influenced by their suffixation [17], [19]. Words with rich morphology raise a question on the possible differences in the timing of lexical access depending on word complexity. We assume that multimorphemic words require longer processing time than monomorphemic ones containing the same number of syllables. In addition, we assume that longer lexical access results in longer word duration. The longer activation time (in the case of multimorphemic words) has a curbing effect on processing, including a slowing-down effect on the duration of the words produced.

There are a large number of well-documented factors (physiological, psychical, and language-specific ones) that influence word duration like frequency, the number of syllables, word type, morphological structure, context-related, speaker-related factors, communication situation, topic, etc. [19], [20], [21], [22], [23]. Two of them, frequency and word length are 
primarily decisive for durations. The factor of frequency concerning both stems and various suffixes of the words might change the assumed decompositional lexical access of some multimorphemic words resulting in their whole word behavior [4], [16], [18], [24]. In other words, a frequently used inflected word may behave as an uninflected whole word as to its lexical access. On the contrary, a rarely used word without any suffix may have a lexical access at similar "speed" as in the case of a multimorphemic word. Frequency, however, is not an unambiguous factor. Although there is a decisive cohort of some function and content words that are frequently used across speakers, word frequency heavily depends on the speaker's own language habits which means that frequency is not an attribute of a word but an attribute of an individual's language use. The frequency effect can be compensated for by the large amount of data the investigation focuses on and by spontaneous speech on a general topic where speakers are assumed to use words without restrictions from their mental lexicon. The distribution of words with different lengths is characteristic of a language in fluent speech and influences their temporal patterns. Words consisting of more syllables are produced faster than words consisting of fewer syllables due to the reduction phenomenon [25], [26].

Among the speaker-related factors influencing word duration, age is also a decisive factor. The assumed durational differences between monomorphemic and multimorphemic words depending on age may add new insights into the morphologically defined temporal patterns of words. Speaking behavior changes in parallel with increasing age due to various anatomical, physiological and psychic factors, as well as the speakers' cognitive workload [27], [28], [29], [30]). Typical ageing influences all factors that are responsible for spontaneous speech, such as breathing, articulation, control over all patterns of speaking, including memory and attention [31]. Findings reported on age-specific decrease of the speed of articulation gestures, durations of segments, words, pauses, phrases and of speech tempi [21], [32], [33]. In the elder, slow speech rate may be relevant to physical changes such as decrease of the fast muscle fibers, reduction of natural jaw oscillation frequency with weak muscle, and loss of tongue volume. The question arises whether the temporal patterns of monomorphemic and multimorphemic words are similar in old age as in young speakers. Would the slowing-down speech behavior of old people neutralize the difference of lexical access and its durational outcome in the case of different word structures? Does old speakers' greater speaking routine help to accommodate the different routes of lexical access?

In our study, we intended to provide a data-driven approach to shed light on the effects of word complexity on word durations in spontaneous Hungarian utterances. We assume that the durations of words may carry information about their storage and access specification. The temporal interrelations of suffixed words as opposed to words without any suffix may reflect the route of lexical access followed by possible execution differences in time [3], [34], [35]. It is assumed that words are produced shorter if accessed from a single place (stem) and longer if accessed from different places (stem + suffix). In this study, only nouns were considered since the differentiation of inflected and uninflected forms are, in general, clearer in nouns than in verbs (e.g., vendég 'guest', vendéget 'guest' + Acc.', vendégnek 'guest' + Dat.').

Hungarian is an appropriate language for analysis to obtain answers for the above-mentioned questions. It is an agglutinative language (Finno-Ugric language family). Nouns, that form the speech material of the present study, have a rich morphology and an extensive system of affixation (case markings are used extensively with nouns). The syntactic and semantic functions of noun phrases are primarily expressed via suffixes. Suffixation requires several phonological rules to be performed at morpheme boundaries (hiatus, various types of assimilation). Hungarian nouns may contain several syllables, easily up to 7 or 8 in a word form. The average number of syllables per word produced by adults in spontaneous Hungarian is 3.5. Word stress invariably falls on the initial syllable although in spontaneous speech not all words carry stress [36].

This study focuses on the temporal patterns of nouns with and without suffixes with various lengths produced by young and old native Hungarian speakers. Four hypotheses were defined. (i) Both mono- and multimorphemic nouns would be longer in old than in young speakers. (ii) Suffixed nouns produced by young speakers would show longer durations as opposed to those of monomorphemic nouns. (iii) Suffixed nouns produced by old speakers would show longer durations as opposed to those of monomorphemic nouns. (iv) The durational differences between monomorphemic and multimorphemic nouns would be stable across various lengths.

\section{Methodology}

Spontaneous speech samples of twenty native Hungarianspeaking subjects were selected randomly (with the exception of age and gender) from the BEA Hungarian speech database [37]. Two groups of participants were formed, one for young and one for old speakers ( 5 females and 5 males were in each group). The mean age of young speakers was 25 years $( \pm 2$ years) while that of old speakers was 80 years ( \pm 2 years). All speakers had age-specific normal hearing. None of them had any articulation or speech defects. Speakers had either a secondary education or a university degree, equally distributed in both groups. All of them had a similar socio-economic status and lived in a large city.

During the sessions, participants were asked to speak about their family, life, hobby, and to share their opinion on a specific topic raised by the interviewer according to the protocol of the database. More than 11 hours of Hungarian spontaneous speech material was analyzed. The average duration of recording per subject was 36 minutes. All recordings were made in the same sound-attenuated room, under identical technical conditions using an Audiotechnica AT4040 cardioid condenser microphone connected directly to a computer using GoldWave to record samples at $44.1 \mathrm{kHz}, 16$ bits, monaurally. This means that all speakers came to the same place for recording (Phonetics Laboratory, Linguistics Institute, Budapest).

The speech material was manually annotated at the word level by a trained transcriber and checked by the first author (both of them are phoneticians and native speakers of Hungarian). The disagreement between the annotators was less than $2 \%$. In cases of disagreement, a third phonetician was asked to decide. Transcription was done in Praat [38].

Word boundaries were identified in the waveform signal and spectrogram display via continuous listening to the words according to usual acoustic-phonetic criteria for onset and offset of nouns (closure and release of obstruents, onset and offset of voicing, as well as second formant information were also considered). The durations of the nouns were obtained automatically using a specific script. The following criteria were defined and followed in noun selection: (i) nouns were considered 
that consisted of 2, 3 and 4 syllables, (ii) they could be either stems or suffixed forms (in this latter case one stem and one suffix was considered), (iii) all suffixes followed the stem and were the last syllables of the nouns, (iv) suffixes were those indicating grammatical relationships, plurals of the nouns as well as various personal and possessive suffixes (e.g., - ban/ben 'in', -nak/nek 'for', suffixes of plural, possessive), (v) the majority of the suffixes consisted of two or three segments while one-segment suffixes occurred rarely since they appear frequently with a rule-based liaison in the word form (e.g., hollo 'raven' and holló/k 'ravens' where [k] stands for Plural vs. pad 'bench' and pad/ok 'benches' where [k] stands for Plural and the preceding [o] is a linking vowel). Reasons for exclusion of nouns are as follows: (i) no compounds (i.e., two stems) were considered, (ii) no nouns were selected where two identical segments (one of the last and another one of the first segment of the following word) were produced, e.g., halat tavaly 'fish + Acc. last year' (because of the uncertainty of boundary marking), (iii) no words were considered that were either preceded or followed by silent or filled pauses (to avoid phrase/syllable final lengthening), (iv) nouns containing prolonged segments (either as disfluencies or reflections of emotion) were excluded. Efforts were made to control prosody and syntactic characteristics that might influence the duration of nouns by the relatively large quantity of analyzed items. Word stress on the first syllable of words made it easy to control for the effect of stress patterns. Examples: kaktusz 'cactus', szerkezet 'construction', gimnázium 'high school' vs. helyen 'on place', asztalban 'in (a) table', egyetemek 'university + Plural'. The number of segments of uninflected and inflected nouns were balanced in both age groups. The number of words was balanced across the number of syllables and suffixation of the nouns, as well as across age groups. Analysis was carried out concerning the repetition of nouns within a speaker and across speakers. The repeated word forms (the same stem and the same stem and suffix) were less than $4 \%$.

A total of 3,182 nouns were analyzed, 1,602 of them were produced by young while 1,580 by old speakers. The number of the monomorphemic nouns was 649 in young and 609 in old speakers while that of the multimorphemic words was 953 in young and 971 in old speakers. The numbers of nouns across various lengths of words reflect their typical distributions in spontaneous Hungarian.

All statistical analyses were performed using R [39]. The Kruskal-Wallis-test and Nemenyi post-hoc tests were used to determine whether there are any statistically significant differences in duration of nouns among the means of 10-10 speakers within the young-old-age groups [40]. To assess effects of suffix and age on duration of nouns, a linear mixed effects model (LMM) with random-effect intercepts was run, with duration (in $\mathrm{ms}$ ) as the dependent variable, syllable $(2,3$, 4), suffix (no, yes), and age (young, old) as the fixed effects, as well as participant (speaker) as random effects. The LMM analysis was performed using the lme4 and lmerTest packages [41], [42]. Post-hoc tests with Bonferroni correction were performed as implemented in the emmeans package [43].

\section{Results}

The mean value of monomorphemic nouns turned out to be 497 $\mathrm{ms}(\mathrm{SD}=165.1 \mathrm{~ms})$ while the mean value of multimorphemic nouns was $634 \mathrm{~ms}(\mathrm{SD}=168.3 \mathrm{~ms})$ irrespective of the number of syllables the noun consisted of and of age. Naturally, overlaps of durational values were found in all cases due to the effects of various factors. To start analysis, young and old speakers' noun durations were compared within each age group (Figure 1). No statistically significant differences were found among the young speakers (Kruskal-Wallis-test: $\chi^{2}(9)=2.21$, $p=0.988$ ) while the old speakers' durations turned out to be significantly affected by 'speaker' $\left(\chi^{2}(9)=22,97, p=0.006\right)$. However, according to the post-hoc Nemenyi-test, only one speaker's (O5) values differed significantly from those of two other speakers (O2: $p=0.010$ and $\mathrm{O} 9: p=0.027)$.

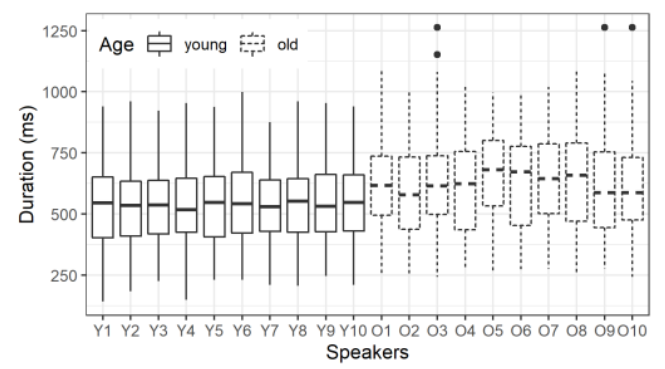

Figure 1: Durations of analyzed Hungarian nouns produced by young and old speakers (medians and interquartile ranges).

Figure 2 summarizes the detailed durational values. The results of the LMM analysis showed a significant main effect for all examined factors: syllable, complexity, and age $(F(2$, $3152.6)=2157.13, p<0.001 ; \quad F(1,3152.6)=433.31, p<$ $0.001), F(1,18.7)=123.19, p<0.001$, respectively).

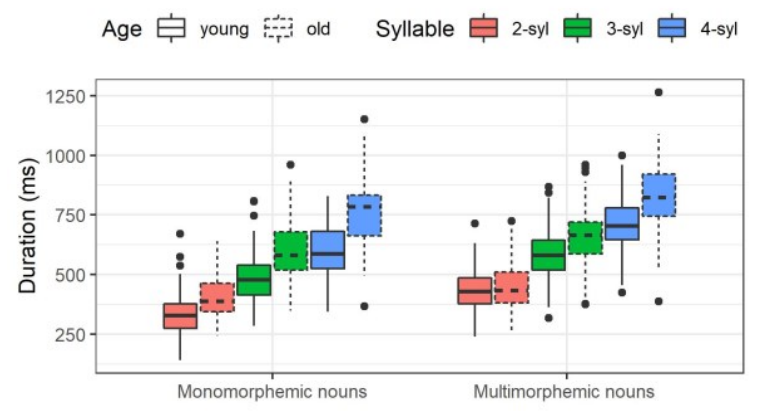

Figure 2: Durations of Hungarian monomorphemic and multimorphemic nouns according to their lengths produced by young (solid line) and old (dotted line) speakers (medians and interquartile ranges).

Post-hoc analysis was performed in the case of the factor 'length' (3 possible numbers of syllables that the nouns contained). All paired comparisons confirmed that each group differed significantly from the others ( $p<0.001$ in all cases).

Age was one of the main factors of analysis. As expected, young speakers produced shorter nouns than old speakers did. The mean value of all nouns produced by young speakers is 536 $\mathrm{ms}(\mathrm{SD}=156.3 \mathrm{~ms})$ while that of all nouns produced by old speakers is $625 \mathrm{~ms}(\mathrm{SD}=190.9 \mathrm{~ms})$. The nouns with diverse numbers of syllables showed also age-specific differences. The 2-, 3- and 4-syllabic monomorphemic and multimorphemic nouns produced by young speakers were significantly shorter than those produced by old speakers. The smallest difference was found in the 2-syllabic mono- and multimorphemic nouns (with no durational differences in the latter case between young and old speakers) while the largest differences were found in the 4-syllabic monomorphemic nouns. The durational 
differences depending on age were more pronounced in monomorphemic nouns as opposed to multimorphemic nouns meaning that the durations of the old speakers' nouns were relatively long (Table 2, Figure 3).

Table 2: Duration of analyzed nouns (in ms) according to length, complexity, and age.

\begin{tabular}{|c|c|c|c|c|}
\hline \multirow{2}{*}{$\begin{array}{c}\text { Number } \\
\text { of } \\
\text { syllables } \\
\text { of nouns }\end{array}$} & \multicolumn{2}{|c|}{$\begin{array}{c}\text { Monomorphemic nouns } \\
\text { (mean/SD) }\end{array}$} & \multicolumn{2}{c|}{$\begin{array}{c}\text { Multimorphemic nouns } \\
\text { (mean/SD) }\end{array}$} \\
\cline { 2 - 5 } & $\begin{array}{c}\text { Young } \\
\text { speakers }\end{array}$ & $\begin{array}{c}\text { Old } \\
\text { speakers }\end{array}$ & $\begin{array}{c}\text { Young } \\
\text { speakers }\end{array}$ & $\begin{array}{c}\text { Old } \\
\text { speakers }\end{array}$ \\
\hline 2 & $331 / 78.5$ & $405 / 80.0$ & $434 / 95.9$ & $444 / 96.4$ \\
\hline 3 & $479 / 89.4$ & $597 / 118.7$ & $576 / 92.9$ & $659 / 108.7$ \\
\hline 4 & $600 / 103.4$ & $766 / 147.0$ & $715 / 102.1$ & $827 / 122.6$ \\
\hline
\end{tabular}

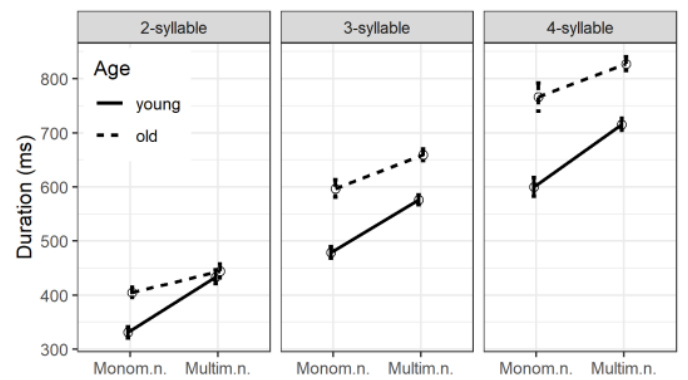

Figure 3: Durations of analyzed nouns (in $\mathrm{ms}$ ) according to length, complexity, and age. Means and $95 \%$ confidence intervals.

The analysis of interactions, built in LMM, provided further results. Out of the 4 interactions ( 3 two-way and a three-way), two turned out to be significant and both of them were connected to age (syllable $\times$ age: $F(2,3152.6)=49.20$, $p<0.001$, and suffix $\times$ age: $F(1,3152.6)=43.44, p<0.001)$.

Along with increasing number of syllables of the nouns, old speakers produced increasingly longer nouns with the mean values of $423 \mathrm{~ms}, 637 \mathrm{~ms}$ and $811 \mathrm{~ms}$ (Figure 4, left side). The durations of the nouns produced by young speakers, however, showed a moderate increase (mean values: $379 \mathrm{~ms}, 537 \mathrm{~ms}$ and $682 \mathrm{~ms}$ ). The mean differences are $214 \mathrm{~ms}$ and $174 \mathrm{~ms}$ in old speakers while $158 \mathrm{~ms}$ and $145 \mathrm{~ms}$ in young speakers (respectively).

An opposite effect could be seen analyzing the interactions of noun complexity and age (Figure 4, right side). As expected, the multimorphemic nouns were longer than the monomorphemic ones (in each age group), the mean difference was more pronounced in young speakers (means in old speakers are $547 \mathrm{~ms}$ and $674 \mathrm{~ms}$, the difference was $127 \mathrm{~ms}$ while in young speakers: $451 \mathrm{~ms}$ and $594 \mathrm{~ms}$, the difference: $143 \mathrm{~ms}$ ).
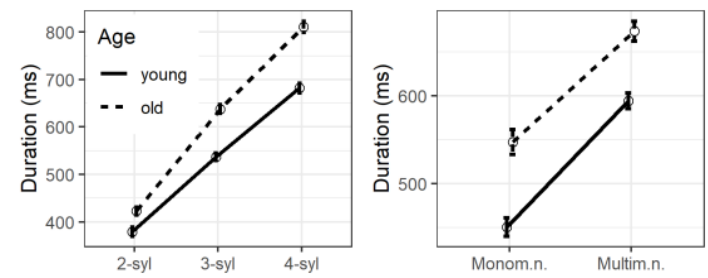

Figure 4: Significant interactions in the LMM: syllable number $\times$ age (left) and suffix $\times$ age (right).

\section{Discussion}

This study analyzed the morphologically simple (stems) and complex (suffixed) Hungarian nouns produced by young and elderly speakers. We assumed that both mono- and multimorphemic nouns would be longer in old than in young speakers which proved to be true. In general, it is not a surprise to see the reflections of old age in slower word production [21], [27], [30]. However, it emerged that the increasing lengths of all nouns analyzed resulted in greater differences in old than in young speakers (Figure 4, left). This specific difference may be explained by both the old speakers' slower articulation of relatively long stems and slower lexical access due to the elderly's larger lexicon (slow retrieval among many items).

As expected, the durations of the suffixed nouns turned out to be statistically longer in both age groups than those of the monomorphemic ones across diverse lengths. The durational difference seems to support the existence of the morphologically decomposed forms of storage and the decomposed route of access in Hungarian nouns with complex morphology. Consequently, speakers needed more time to access suffixed nouns than stems.

We assumed that the durational differences between monomorphemic and multimorphemic nouns would be stable across various lengths of the nouns in both age groups. The data, however, partly contradicted this assumption. The durations of multimorphemic nouns increased to a smaller extent in old speakers compared to the young ones. It seems that the lexical access of the noun stem provides some difficulty for the elderly, effecting a slower process, but accessing and combining suffixes to (finally) activated stems does not. After having accessed the stem, suffixation (including the necessary morphophonological rules) is relatively fast that underpins the temporal patterns of the suffixed nouns.

We suggest that this finding can be explained by the old speakers' greater speaking routine, particularly in accessing suffixes and performing morpho-phonological rules in spontaneous utterances. The activation of suffixed nouns from two places of the mental lexicon does not require great cognitive workload from old speakers, and the fast composition of complex words may be attributed to enhanced neural connectivity (acquired from long experience of language use).

The temporal reduction of words could be experienced with all the nouns analyzed in this study in both age groups irrespective of their complexity [25], [26], [44]. This finding refers to the fact that reduction phenomena are independent of word complexity and age.

\section{Conclusions}

The mental lexicon allows of dual storage and both decomposed and non-decomposed routes of lexical access, at least for Hungarian nouns with various complexity. The noun durations of old speakers are not only longer compared to those of young ones, but the number of syllables nouns contain influences the durations differently depending on age. Speaking routine should be considered in lexical activation.

\section{Acknowledgements}

This research was supported by the Ministry of Innovation and Technology of Hungary from the National Research, Development and Innovation Fund, financed under the ELTE TKP2020IKA-06 funding scheme. 


\section{References}

[1] A. Caramazza, A. Laudanna, and C. Romani, "Lexical access and inflectional morphology," Cognition, vol. 28, no. 3, pp. 297-332, 1988.

[2] W. J. M. Levelt, "Speaking: From Intention to Articulation." Cambridge, MA: MIT Press, 1989

[3] A. Roelofs, "Testing a non-decompositional theory of lemma retrieval in speaking: retrieval of verbs," Cognition, vol. 47, pp. 59-87, 1993.

[4] K. Rastle, M. H. Davis, and B. New, "The broth in my brother's brothel: Morpho-orthographic segmentation in visual word recognition," Psychonomic Bulletin and Review, vol. 11, no. 6, pp. 1090-1098, 2004.

[5] B. Zhang and D. Peng, "Decomposed storage in the Chinese lexicon," in H. Ch. Chen and O. J. L. Zheng (eds.), Language processing in Chinese. Amsterdam: Elsevier, 1992, pp. 131-149.

[6] N. Kazanina, G. Dukova-Zheleva, V. Kharlamov, and K Tonciulescu, "Decomposition into multiple morphemes during lexical access: A masked priming study of Russian nouns". Journal of Language and Cognitive Processes, vol. 23, no. 6, pp. 800-823, 2008.

[7] L. Burzio, "Paradigmatic and syntagmatic relations in Italian verbal inflection," in J. Auger, C. Clements, and B. Vance (eds.), Contemporary Approaches to Romance Linguistics. Amsterdam/Philadelphia: John Benjamins, 2004, pp. 17-44.

[8] J. P. Blevins, "Word-based morphology," Journal of Linguistics, vol. 42 , pp. 531-573, 2006

[9] M. Maratsos, "More over-regularizations after all," Journal of Child Language, vol. 28, pp. 32-54, 2000.

[10] H. Clahsen, P. Prüfert, S. Eisenbeiss, and J. Cholin, "Strong stems in the German mental lexicon: Evidence from child language acquisition and adult processing," in I. Kaufmann and B. Stiebels (eds.), More than Words. A Festschrift for Dieter Wunderlich. Berlin: Akademie Verlag, 2001, pp. 91-112.

[11] H. Schriefers, A. D. Friederici, and P. Graetz, "Exploring the time course of lexical access in language production: Picture-word interference studies". Journal of Memory and Language, vol. 29, pp. 86-102, 1990

[12] M. Ferro, G. Pezzulo, and V. Pirrelli, "Morphology, memory and the mental lexicon," Lingue e Linguaggio, vol. IX, no. 2, pp. 199 238, 2010.

[13] K. Gor and S. Jackson, "Morphological decomposition and lexical access in a native and second language: A nesting doll effect". Language and Cognitive Processes, vol. 28, no. 7, pp. 10651091, 2013.

[14] G. L. Estivalet and E. F. Meunier, E. 2015. Decomposability and mental representation of French verbs. Frontiers in Human Neuroscience, vol. 8, pp. 91-100, 2015.

[15] W. Marslen-Wilson, L. Tyler, R. Waksler, and L. Older, "Morphology and meaning in the English mental lexicon," Psychological Review, vol. 101, no. 1, pp. 3-33, 1994.

[16] M. Saxton, "Child language: Acquisition and Development". Thousand Oaks, CA.: Sage Publication, 2010.

[17] M-J. Budd, S. Paulmann, Ch. Barry, and H. Clahsen, "Brain potentials during language production in children and adults: An ERP study of the English past tense". Brain and Language, vol. 127, pp. 345-355, 2013.

[18] L. Stockall and A. Marantz, "A single route, full decomposition model of morphological complexity: MEG evidence". The Mental Lexicon, vol. 1, no. 1, pp. 85-123, 2006.

[19] B. L. Losiewicz, "Word frequency effects on the acoustic duration of morphemes," Journal of the Acoustical Society of America, vol. 97, no. 5, pp. 32-43, 1995.

[20] A. Bell, J. M. Brenier, M. Gregory, C. Girand, and D. Jurafsky, "Predictability effects on durations of content and function words in conversational English". Journal of Memory and Language, vol. 60 , no. 1, pp. 92-111, 2009.

[21] E. Jacewicz, R. A. Fox, and L. Wei, "Between-speaker and within-speaker variation in speech tempo of American English,' Journal of the Acoustical Society of America, vol. 128, no. 2, pp. 839-850, 2010
[22] Z. Yang, V. Ramanarayanan, D. Byrd, and S. Narayanan, "The effect of word frequency and lexical class on articulatory-acoustic coupling," in Proceedings of INTERSPEECH 2013, Lyon, France. Aug. 25-29, 2013, pp. 973-977.

[23] P. Milin, B. L. Feldman, and E. Smolka, "Models of lexical access and morphological processing," in E. M. Fernández and C. H. Smith (eds.), The Handbook of Psycholinguistics. Wiley Online Library, 2017. pp. 240-268.

[24] C. Lignos and K. Gorman, "Revisiting frequency and storage in morphological processing," Proceedings of CLS, vol. 48, pp. 447461, 2012.

[25] J. Mačutek, R. Čech, and J. Milička, "Menzerath-Altmann Law in syntactic dependency structure," Proceedings of the 4th International Conference on Dependency Linguistics (Depling 2017), Pisa, Italy, pp. 100-107, 2017.

[26] I. M. Cramer, "Das Menzerathsche Gesetz," in R. Köhler, G. Altmann and R. G. Piotrowski (eds.), Quantitative linguistics. An International Handbook. Berlin, New York: De Gruyter, 2005, pp. 659-688.

[27] C. Rodriguer-Aranda and M. Jakobsen, "Differential contribution of cognitive and psychomotor functions to the age-related slowing of speech production," Journal of the International Neuropsychological Society, vol. 17, no. 5, pp. 1-15, 2011.

[28] S. A. Xue, G. J. Hao, "Changes in the human vocal tract due to aging and the acoustic correlates of speech production: A pilot study," Journal of Speech, Language, and Hearing Research, vol. 46, no. 3, pp. 689-701, 2003

[29] R. I. Zraick, M A. Gentry, L. Smith-Olinde, B. A. Gregg, "The effect of speaking context on elicitation of habitual pitch," Journal of Voice, vol. 20, no. 4, pp. 545-554, 2006.

[30] J. Bóna, "Temporal characteristics of speech: The effect of age and speech style," Journal of the Acoustical Society of America, vol. 136, no. 2, pp. EL116-121, 2014.

[31] D. M. Burke, D. G. Mackay, and L. E. James, "Theoretical approaches to language and aging," in T. Perfect and E. Maylor (eds.), Models of Cognitive Aging. Oxford: Oxford University Press, 2000, pp. 204-237.

[32] A. R. Fletcher and M. J. McAuliffe, "The relationship between speech segment duration and vowel centralization in a group of older speakers," Journal of the Acoustical Society of America, vol. 138, no. 4, pp. 2132-2148, 2015.

[33] M. Gósy, "Temporal and disfluency patterns of narratives in old age," in A. Uberman and M. Trinder (eds.), Text Sentence Word: Studies in English Linguistics IV. Rzeszów: Wydawnictwo Uniwersytetu Rzeszowskiego, 2021, pp. 51-61.

[34] J. Vannest and J. E. Boland, "Lexical morphology and lexical access," Brain and Language, vol. 68, no. 1-2,pp. 324-332, 1999.

[35] A. Onysko and S. Michel (eds.), "Cognitive perspectives on word formation." Berlin, New York: De Gruyter, Mouton, 2010.

[36] P. Siptár and M. Törkenczy, "The Phonology of Hungarian." Oxford: Oxford University Press, 2000

[37] M. Gósy, "BEA - A multifunctional Hungarian spoken language database". The Phonetician, vol. 105/106, pp. 50-61, 2012.

[38] P. Boersma and D. Weenink, "Praat: doing phonetics by computer," Version 5, 2018, retrieved from http://www.praat.org/

[39] R Core Team, " $R$ : A Language and Environment for Statistical Computing." Vienna, Austria: R Foundation for Statistical Computing, 2021

[40] A. Signorell et mult. al., "DescTools: Tools for descriptive statistics." R package version 0.99.40, 2021. https://cran.rproject. org/package $=$ DescTools

[41] D. Bates, M. Mächler, B. Bolker, and S. Walker, "Fitting linear mixed-effects models using lme4," Journal of Statistical Software, vol. 67, no. 1, 2015

[42] A. Kuznetsova, P. B. Brockhoff, and R. H. B. Christensen, "ImerTest Package: Tests in linear mixed effects models," Journal of Statistical Software, vol. 82, no. 13, 2017.

[43] R. V. Length et. al., "Emmeans: Estimated Marginal Means", Aka Least-Squares Means, 2021.

[44] M. Aylett and A. Turk, "The smooth signal redundancy hypothesis: A functional explanation for relationships between redundancy, prosodic prominence, and duration in spontaneous speech," Language and Speech, vol. 47, pp. 31-56, 2004 